\title{
POLÍTICAS SOCIAIS \\ E POLÍTICAS DE CULTURA: \\ TERRITÓRIOS \\ E PRIVATIZAÇÕES CRUZADAS
}

\author{
Cibele Saliba Rizek
}

\begin{abstract}
R E S U M O O artigo se baseia em pesquisa que apontou para novas formas de captação de recursos por meio da promoçâa de práticas culturais que se interligam à gestão de serviços públicos de saúde na Zona Leste da Cidade de São Paulo, sob a direçáo de organizaçôes sociais privadas. O cruzamento entre modos de captação, gestâo terceirizada da cultura e equipamentos de saúde aponta para uma intersetorialidade inédita dessas práticas, o que configura o que poderia ser identificado como um planejamento social privado, redesenhando formas de atuação e margens do Estado por meio de um conjunto de relaçôes entre os programas sociais e a população em condiçôes de pobreza na maior cidade brasileira. Os bairros da última periferia Leste da cidade de São Paulo conformam assim um terreno de experimentaçôes dessas práticas cruzadas para além das caracterizaçōes clássicas das zonas periféricas das grandes metrópoles brasileiras que apontavam para a precariedade das condiçôes de vida bem como para o nascedouro de movimentos sociais, suas demandas, sujeitos e linguagens de direitos, tal como foram percebidos e enunciados a partir do final dos anos oitenta do século XX.
\end{abstract}

P A L A V R A S - C H A V E Políticas sociais; políticas públicas; privatizaçâo; periferias urbanas

\section{APRESENTAÇÃO}

Este texto tem como objetivo apresentar achados de pesquisa que apontam para um conjunto de novas formas de captação de recursos por meio de eventos e práticas culturais e de gestão de serviços privatizados de saúde na zona leste da cidade de São Paulo. O cruzamento entre modos de captaçáo, gestão terceirizada da cultura e de açóes e equipamentos de saúde apontam para a intersetorialidade dessas práticas de modo inédito, conformando o que poderia ser identificado como um planejamento social privado minucioso por parte de organizaçóes sociais de cultura e de saúde que redesenham formas de atuação e margens do estado nas suas relaçóes com programas sociais e com a população em condiçôes de vulnerabilidade na maior cidade brasileira.

Alguns bairros da periferia leste da cidade de São Paulo conformam assim um terreno de experimentaçóes dessas práticas cruzadas para além das caracterizaçóes clássicas das zonas periféricas das grandes metrópoles brasileiras que apontavam para a precariedade das 
1 Esse conjunto de achados de pesquisa dizem respeito especificamente a bairros da zona leste da cidade de São Paulo, sobretudo no que diz respeito à privatização $e$ gestão dos equipamentos de saúde. Os achados de pesquisa iniciais que forneceram as pistas para uma incursão mais aprofundada na questão são provenientes de anos de acompanhamento de atividades e práticas em Cidade Tiradentes - no extremo leste do município que pode ser caracterizado como um dos últimos bairros da cidade a se formar. Cidade Tiradentes ficou conhecida como "o maior conjunto habitacional da América Latina", tendo sido formada a partir de remoções provenientes de obras e de intervenções por toda a cidade de São Paulo. Apesar de inicialmente constituída por pequenos edifícios da COHAB, o bairro cresce a partir de combinações entre loteamentos e edifícios constituídos de forma regular e pedaços de território ocupados irregularmente. A presença de assentamentos regulares ao lado de outros pouco ou nada regulares e/ ou regularizáveis - favelas, habitações que se transformam em estabelecimentos comerciais, edifícios da CO$H A B$, terrenos e encostas também ocupados irregularmente, acabou por configurar uma população de cerca de 215.000. 0 bairro cresce mais do que a média dos bairros paulistanos e tem $72 \%$ de sua população ganhando em média 2 salários mínimos mensais (Cf. <http:// www.prefeitura.sp.gov.br/ cidade/secretarias/upload/ saude/arquivos/publicacoes/ Boletim CEInfo Censo 02. pdf>, consultado em maio de 2012). Ao lado de Cidade Tiradentes, Guaianases é um bairro também constituído por populações de baixa renda e conta - somando-se a população de Lajeado - com cerca de 250.000 habitantes. Esses bairros estão a cerca de $35 \mathrm{~km}$ do centro da cidade. Guaianases conta com o serviço de trens da CPTM e Cidade Tiradentes apenas com 0 serviço de algumas linhas de ônibus, reconhecidamente insuficientes para o transpor- condiçóes de vida bem como para o berço de movimentos sociais que se deslocavam das reivindicaçóes relativas às carências para a constituição de demandas, sujeitos e linguagens de direitos, tal como foram percebidos e enunciados a partir do final dos anos 80 do século $\mathrm{XX}$. O que esses achados de pesquisa parecem apontar é um terreno fértil para a ação de grupos e de empreendimentos privados que crescem em espiral oferecendo, gerindo e promovendo serviços, açôes e práticas no campo da assistência, conformando novas formas de gestão do cotidiano dessas populaçóes e reconfigurando as relaçôes entre o Estado e seus serviços, as populaçôes que habitam esses territórios e a plêiade de programas e políticas sociais que vêm reconfigurando as dimensões cotidianas, as práticas de consumo, formas de sociabilidade e formas de expressão dessas populaçóes.

\section{INDÍcIOS E ACHADOS}

Em visitas a campo e a partir da sistematização de informaçóes de pesquisa, a coincidência entre um conjunto de iniciativas de cunho cultural e a gestão de programas e equipamentos de saúde começou a se delinear como inquietação. Afinal como se cruzavam escolas de música, faculdades, oficinas culturais, grandes atividades culturais em eventos importantes da agenda paulistana e hospitais, postos e agentes e programas de saúde e assistência à família no extremo leste da cidade de São Paulo? Essas indagaçóes são o ponto de partida deste texto.

A partir de informaçóes dispersas, surgiram indícios que apontavam para uma política inusitada de captação de recursos e de investimento em saúde na zona leste ${ }^{1}$ da cidade de São Paulo. O primeiro indício provém da terceirização dos serviços de saúde que foi se estendendo pela regiáo como parte de uma política de privatização da gestáo de saúde no município e no estado de São Paulo. Esses mecanismos de transferência de gestáo da saúde do Estado para organizaçóes sociais tiveram início a partir do final da gestão Erundina, em 1992 - e se estenderam até hoje. O segundo indício decorre da presença concomitante de instituições encabeçadas por religiosas católicas tanto em hospitais e programas de saúde - como o Estratégia Saúde da Família e seus equipamentos de ancoragem, até postos de saúde que atendem parcela nada desprezível da população que habita Cidade Tiradentes e outros distritos da zona leste de São Paulo - como em açóes, instituiçóes e programas de cunho cultural. A Organização de Saúde STX,2 além do hospital municipal de Cidade Tiradentes, também é responsável pela gestão de grande hospital, em Itaquera, parcela mais consolidada da periferia da cidade e local do estádio que sediará a abertura da Copa do Mundo de 2014. As mesmas irmãs deram origem, há algumas décadas, a uma escola privada de cunho religioso de primeiro e segundo grau, a uma faculdade de música, moda e design entre outros cursos, outra unidade de ensino superior em Itaquera que abriga inclusive um curso de medicina e programas privados e pós-graduação, bem como uma oficina cultural/escola de música da cidade, originalmente do estado de Sáo Paulo; a OS Cultural também se faz presente em grandes eventos culturais como o Festival de Inverno de Campos do Jordáo, ${ }^{3}$ bem como na gestáo terceirizada de evento eleitoralmente significativo na cidade de São Paulo: a Virada Cultural que consiste em espetáculos nas ruas, praças e espaços da cidade durante 24 horas.

Assim, para entender os processos que têm lugar no complexo de instituiçôes de saúde geridas pelas organizaçóes STX, é preciso poder perceber como se entrecruzam serviços e captação de recursos por meio de um mecanismo de privatização da cultura e 
de terceirização dos equipamentos e serviços públicos de saúde de modo entrecruzado. ${ }^{4}$ Esse achado de pesquisa, ausente na literatura sobre cultura e saúde em São Paulo e no Brasil, parece se constituir em um caso único que cruza gestóes e arbitragens privadas tanto das atividades culturais quanto de dimensóes relativas à assistência à saúde, em suas injunçōes com a assistência social às famílias. ${ }^{5}$

Para compreender esse cruzamento, é preciso mencionar que esses processos têm por base dimensóes legais instituídas em momentos e em instâncias diversas ao longo das últimas décadas no Brasil. Outro elemento a destacar diz respeito ao fato de que é no estado de São Paulo que esses dois expedientes se cruzaram significativamente. Trata-se de uma intrincada forma de engenharia organizacional que combina investimentos e aplicação de recursos cruzando setores de forma bastante complexa, o que requer uma fina apreensão e manejo dos meandros dos processos de financiamento assim como uma perspectiva cruzada que permita caminhar pelos processos de terceirizaçáo da saúde no estado que parece ser a meca brasileira da privatização dos serviços públicos, graças a duas décadas de governo do PSDB, partido que defendeu os expedientes dessas privatizaçóes e terceirizaçóes, sobretudo dos serviços de saúde. Também é importante notar que esse partido participou de forma significativa das últimas duas gestóes municipais, depois de ter derrotado a prefeita Marta Suplicy em 2004. Essa confluência entre governos municipal ${ }^{6}$ e estadual é um elemento importante para a captação e investimento que se pretende discutir como fato consumado no estado de São Paulo, mas que se desenha como tendência em outros estados e municípios do país, a julgar por algumas linhas de financiamento do Ministério da Cultura, em especial as que vinculam Saúde e Cultura. ${ }^{7}$

\section{A LEI ROUANET}

Graças a um conjunto importante de transformaçóes que ganharam fôlego nos últimos 30 ou 40 anos - tanto no Brasil quanto em âmbito mundial -, as grandes empresas, o Estado, bancos e corporaçóes que dão materialidade à forma organizacional do capital mundializado e financeirizado descobriram a cultura e a arte como negócio, como nova fronteira de investimento e como possibilidade de gestão, cálculo e administração em uma escala inédita. Esse processo ganhou densidade e visibilidade no Brasil graças à Lei Rouanet - finalmente implementada entre o final dos anos 1980 e início dos anos 1990. Trata-se de uma lei de incentivo por meio de benefícios fiscais que possibilita que parte das pessoas físicas e jurídicas apliquem parcela de imposto devido à Uniáo em atividades culturais, conseguindo benefícios obtidos sobre o valor do incentivo, viabilizando iniciativas culturais. A mesma medida jurídica também instituiu o Fundo Nacional de Cultura e o Programa Nacional de Apoio à Cultura. $\mathrm{O}$ apoio às atividades culturais pode, desde entáo, ser estabelecido por doações e patrocínio, o que favorece e se entrelaça às práticas de marketing empresarial. Uma das questôes importantes sobre a Lei Rouanet e a política brasileira de cultura diz respeito à crescente hegemonia do financiamento privado das atividades de cultura, bem como terceirizaçôes e privatizaçôes de teatros e agências do Estado, entregues a organizaçôes privadas sob a forma de OSs (organizaçóes sociais) e/ou ONGs. A instituição desse conjunto de benefícios fiscais acabou por se configurar em uma política cultural de privatizaçáo dos recursos e dos processos de arbitragem sobre objetos de investimento ou, pelo menos, de crescente participação das formas privadas na gestáo e na escolha de práticas e objetos de financiamento. Ganha relevância o acoplamento entre interesses dos te adequado da população. A partir de achados e informações dispersas, seguindo pistas e indícios, acabei por perceber que grande parte dos equipamentos e serviços de saúde das periferias paulis tanas está sendo gerida por contratos com organizações sociais, como se constatará adiante. A especificidade das OSs identificadas no texto está assim no cruzamento entre as atividades de saúde e de cultura.

2 Nome fictício. A necessidade de nomes fictícios prejudica também algumas menções de fontes.

3 Grande festival de música que acontece anualmente, compondo-se de concertos, apresentações, cursos e oficinas de convidados nacionais e internacionais.

4 Em visita ao Hospital de Itaquera, em maio de 2011, um dos responsáveis pelo serviço de oncologia pediátrica afirmou que a estratégia era a captação de recursos pelos grandes eventos culturais para a manutenção do serviço de ponta no hospital de Itaquera. Essa pista deu origem ao mapeamento desse texto.

5 Ver Isabel Georges e Yumi Garcia, A produção da "demanda": viés institucional $e$ implicações políticas da terceirização do trabalho social, ANPOCS, Caxambu, 2011.

60 então prefeito de São Paulo foi vice-prefeito da gestão Serra pelo Democratas. Posteriormente concorreu e ganhou a prefeitura da cidade e fundou outro partido sem alteração significativa de suas posturas dentro do espectro político brasileiro.

7 Ver os editais Cultura e Saúde e Rede Saúde e Cultura no sítio <http://www.cultura. gov.br>, consultado em 20 de outubro de 2012.

8 SEGNINI, Liliana. 0 que permanece quando tudo muda. Cadernos do $\mathrm{CRH}$, v. 24, número especial, 2011. 
9 Ver: <www.cultura.gov.br/ apoio_a_projetos>. Consultado em setembro de 2009.

10 A origem da proposta dos CEUs teve lugar na gestão petista de Marta Suplicy (2001/2004) para reforçar a infraestrutura de áreas da cidade relegadas à ausência de equipamentos públicos, de educação e cultura. (Ver: <www.prefeitura. sp.gov.br>, consultado em 15 de agosto de 2012). Os centros de educação unificados foram planejados com três objetivos: “1. Desenvolvimento integral das crianças e dos jovens - reunindo ações educativas da Prefeitura em um polo, para o qual confluem Centro de Educação Infantil (300 vagas), Escola Municipal de Educação Infantil (900 vagas) e Escola Municipal de Ensino Fundamental (1.260 vagas), otimizando equipamentos e serviços. 0 Centro oferece infraestrutura para o desenvolvimento integral da aprendizagem em seus diferentes aspectos; 2. Polo de desenvolvimento da comunidade - os Centros se tornarão polos irradiadores e reorganizadores de relações sociais no bairro [...]; 3. Polo de inovação de experiências educacionais - [...] o objetivo é que - CEU atue como Centro de Referência, estendendo o conhecimento adquirido para as demais escolas da região." O projeto dos CEUs incorporou, assim, uma série de experiências no planejamento e construção de redes educacionais, tanto no aspecto do "continente" (o prédio escolar) como no do "conteúdo". Em 2003 foram entregues 21 unidades, viabilizando mais de 50 mil novas vagas.

11 Segundo a Secretaria de Cultura do Estado de São Paulo, o programa Projeto Guri conta com 51.000 alunos em todo o estado. Esse projeto, considerado o maior programa sociocultural brasileiro, consiste em ocupar as crianças no contraturno escolar com cursos de iniciação, aprendizado e teoria musical. Sua gestão é realizada por duas organizações sociais ligadas à Secretaria de governos de inspiração neoliberal que propuseram a expansão do livre mercado e os interesses das grandes corporaçóes em aumentar seu raio de ação, açambarcando a produção de arte e cultura, minimizando custos por meio de renúncia fiscal e maximizando lucros através dos processos de marketing corporativo.

Essa tendência de aumento do financiamento privado é perceptível desde meados dos anos 1980, ainda que a incidência desses financiamentos sobre a produção cultural ganhe importância a partir de $1995 .{ }^{\circ}$ Observa-se ainda, desde o final dos anos 1990 até meados da primeira década do século XXI, um crescimento vertiginoso do Fundo Nacional de Cultura e o crescimento exponencial concomitante dos recursos investidos através do mecenato, por meio da Lei Rouanet. ${ }^{9}$ Esse mecanismo está na base de toda política de relaçôes entre Estado e capital corporativo, inclusive corporaçôes estatais em relação ao financiamento da cultura. Trata-se, portanto, de renúncia fiscal, de investimento de fundo público por meio de um processo de arbitragem privada.

Parece plausível afirmar que os projetos que recebem mais investimento oriundo do mecenato são os que têm origem em grupos artísticos ou empresários da indústria de entretenimento mais consolidados e/ou com maior expressão e visibilidade midiática. Assim, artistas consolidados, ou o consagradíssimo Cirque de Soleil, receberam recursos oriundos desse mecanismo de parceria Estado/corporaçóes privadas, o que não impediu a cobrança de ingressos em casas de espetáculo localizadas nos grandes eixos de expansão urbana das capitais brasileiras. Cabe ainda destacar a participação significativa de empresas públicas nesse processo de captaçáo - entre elas, a Petrobras, com peso relevante nesse universo de ofertas de possibilidades de financiamento da produção cultural e artística. Assim, em um contexto de políticas que reforçam a importância estratégica do mercado de financiamentos e oportunidades de investimento, o Estado transfere recursos públicos para as grandes corporaçôes e elas definem as diretrizes da relação entre arte, mercado e fundos públicos, programas e modos de investimento. Se são as empresas públicas de caráter ainda predominantemente estatal que estáo entre as maiores financiadoras, podese apontar que há aí uma opção econômica, mas, sobretudo, também política. Trata-se de uma política de gestão das artes por meio de decisôes cujo núcleo se desenha a partir das grandes corporaçóes conformadas como eixos decisórios a respeito do que se financia e do que se promove como práticas culturais no Brasil.

Dessa perspectiva, as artes e espetáculos - em especial as atividades relativas à música e à musica erudita no caso da OS STX - são principalmente modo de captação privada de recursos públicos para, por meio de um conjunto significativo de investimentos, promover o atendimento em saúde com foco na zona leste, de modo associado a um conjunto de programas socioculturais, pelas diversas regiốes da cidade, em especial nos CEUs ${ }^{10}$ onde acontecem as atividades que resultam da gestáo do Projeto Guri. ${ }^{11}$

\section{As atividades da OS Cultural STX contam com os seguintes parceiros:} CTEEP; ${ }^{12}$ Prefeitura do Estado de São Paulo; Instituto Itaú Cultural; Secretaria do Desenvolvimento Social do Estado de Sáo Paulo - Governo Estadual, por meio do Centro De Esporte, Cultura e Lazer; Instituto Abril Cultural; AECID - Embaixada da Espanha no Brasil - Agência Espanhola de Cooperação Internacional para o Desenvolvimento; Camargo Correa; Fundação OSESP; Lei de Incentivo à Cultura - Lei Rouanet. Contam ainda com o apoio institucional da missáo diplomática dos Estados Unidos da América no Brasil. Apontam como suas principais filiações a International Federation of Arts Councils and Culture Agencies; a World Association of Symphonic Bands and Ensembles e a Internacional Society of Performing Arts. 
A OS de Cultura STX constituiu polos importantes do desenvolvimento do Projeto Guri por toda a cidade de Sáo Paulo. Estáo presentes na zona norte atuando nos CEUs Pera Marmelo, Vila Perus e Vila Atlântica; na zona sul, nos CEUs Vila Alvarenga, Cidade Dutra, Casa Blanca, Meninos, PEFI Imigrantes e CEU Navegantes; na zona leste por meio dos CEUs da Vila Curuçá, Jambeiro, Jardim São Carlos, Parque Vereda, Rosa da China e São Mateus; na zona oeste nas Comunidades Harmonia e Ponte Brasilitália; na região central da cidade, em unidades alocadas na Achiropita, nas Casas de Solidariedade I e II e na Julio Prestes.

A OS de Cultura STX define sua inserção no Projeto Guri do Governo do Estado de São Paulo como uma associação entre educação musical e a inclusão sociocultural de crianças e adolescentes. O programa - lançado em 2008 a partir de uma iniciativa da Secretaria de Estado da Cultura de São Paulo - é gerido nesses polos já mencionados pela OS de Cultura STX. Para atingir esse objetivo de educação musical e "inclusão social", a OS conta com um conjunto de atividades definidas como apoio social integrado às crianças e adolescentes, nos termos que se seguem:

O Guri STX conta com uma equipe de assistentes sociais que atuam em sintonia com os educadores e demais funcionários do programa. O serviço social acompanha o dia a dia dos alunos nos polos de ensino, identifica suas possíveis demandas e os encaminha às redes sociais existentes. O objetivo é criar um ambiente favorável ao aprendizado, ajudando a construir a autonomia crítica dos estudantes, famílias e comunidades. Na condição de agentes catalisadores de processos coletivos, os assistentes sociais do Guri STX dedicam-se a facilitar a comunicaçâo entre a cultura escolar e a cultura de origem das crianças e jovens atendidos pelo programa. Os assistentes sociais elaboram, executam e avaliam açóes socioeducativas, preventivas e de enfrentamento de situaçóes emergentes que afetam as crianças e jovens, tais como violência, dificuldades interpessoais e problemas econômicos ou de saúde. Também transmitem aos estudantes e suas famílias conhecimentos de deveres e direitos sociais, incluindo os mecanismos de acesso por meio das políticas públicas e redes sociais já existentes. ${ }^{13}$

Dessa perspectiva, as atividades dos assistentes sociais incluem: visitas domiciliares; atendimentos e encaminhamentos; palestras; oficinas temáticas; reuniōes e capacitações. Cabe salientar que o projeto se inscreve em uma zona de articulação entre ensino musical e trabalho social/inclusão, sendo um dos beneficiários das leis de incentivos fiscais/Lei Rouanet. Nesse caso, a captaçáo se faz inclusive diretamente, como se depreende da citação abaixo:

As empresas tributadas com base no Lucro Real podem destinar até $4 \%$ do seu IR, até o dia 30/12/2011, para nossos projetos culturais, aprovados pelo Ministério da Cultura. Se sua empresa pode se beneficiar da Lei Rouanet, destinando seu IR para o Guri STX, você transformará os seus recursos em Instrumentos Musicais para crianças e adolescentes de 6 a 18 anos, moradoras de regióes de alta vulnerabilidade social da Capital e Grande São Paulo. Nosso projeto está contemplado no artigo 18 da Lei Rouanet, sua empresa poderá abater $100 \%$ do recurso investido em sua declaração de IR. ${ }^{14}$
Estado da Cultura: a Associação Amigos do Projeto Guri - fora da cidade de São Paulo - e a OS STX, responsável por 50 polos na capital, com 13.500 alunos.

12 Trata-se da maior concessionária privada de transmissão de energia elétrica em atuação no país, responsável pela transmissão de quase $100 \%$ da energia elétrica produzida no estado de São Paulo.

13 Sítio da OS, consultado em 18 de agosto de 2012.

14 No sítio já citado.

15 É preciso mencionar que o que aparece neste texto como uma dimensão localizada é um modelo de gestão muito mais amplo. Atualmente, 37 hospitais, 38 ambulatórios, um centro de referência, duas farmácias e três laboratórios de análises clínicas são administrados por esta forma de gerenciamento. Os novos hospitais colocaram a serviço do SS cerca de 4.300 leitos no estado de São Paulo. Esse modelo de gestão privada foi regulamentado pela Lei no 14.132, de 24 de janeiro de 2006 que dispôs sobre a qualificação de entidades sem fins lucrativos como organizações sociais. É possível ainda mencionar algumas dessas organizações, tais como: OS INSTITUTO DE ATENÇÃO BÁSICA E AVANÇADA À SAÚDE - IABAS - AMA SORRISO Contrato de Gestão no 026/2009; OS SANTA CASA DE MISERICÓRDIA DE SANTO AMARO, responsável por PSM José Sylvio de Camargo (Santo Amaro) Contrato de Gestão no 25/2009 (Zona Sul); OS CASA DE SAÚDE SANTA MARCELINA - Microrregião Cidade Tiradentes/Guaianases Contrato de Gestão no 01/2007, Hospital Municipal Cidade Tiradentes Contrato de Gestão no 02/2007, Microrregião Itaim Paulista Contrato de Gestão no 10/2008, Lote 3 PA Atulapa Girão Rabelo - PA Dra. Glória R. Santos Bonfim - PSM Dr. Julio Tupy Contrato de Gestão no 15/2009; OS CENTRO DE ESTUDOS E PESQUISAS DR. JOÃO AMORIM - CEJAM - Microrregião M'Boi Mirim. Contrato de 
Gestão no 03/2007 e Hospital Municipal M'Boi Mirim Contrato de Gestão no 04/2008 (Zona Sul); OS ASSOCIAÇÃO CONGREGAÇÃO DE SANTA CATARINA - Microrregião Cidade Ademar Contrato de Gestão no 05/2008 e Microrregião Socorro/Parelheiros Contrato de Gestão no 11/2008 (Zona Sul); OS ASSOCIAÇÃO PAULISTA PARA O DESENVOLVIMENTO DA MEDICINA - Microrregião Vila Maria/Vila Guilherme Contrato de Gestão no 06/2008 (Zona Norte), Contrato de Gestão № 27/2010 - Território Aricanduva/Sapopemba/ São Mateus Contrato de Gestão no 07/2008 e Lote 1-PSM Augusto Gomes de Matos/ PA São Mateus Zona Leste 1; contrato de Gestão no 23/2009 - OS SANTA CASA DE MISERICÓRDIA DE SÃO PAULO Microrregião Jaçanã/ Tremembé Contrato de Gestão no 08/2008 (Zona Norte). Ver Organizações Sociais no Sistema de Saúde de São Paulo: <www.frentecontraprivatizacaope.com.br/blog/wp.../ DADOS-OSS>.

16 Cf. sítio da os/ aps/ nasf/ asp, consultado em $15 / 08 / 2012$.

\section{SOCIAL, CULTURAL, ASSISTENCIAL - TUDO ISSO E MAIS UM POUCO: AS OS STX ${ }^{15}$}

A partir de seus sítios, além de visitas a campo realizadas em 2010 e 2011 em Cidade Tiradentes, é possível mapear as atividades mais importantes dessas organizaçóes sociais articuladas: a Organização de Saúde e a Organização de Cultura STX.

Do ponto de vista de suas atividades em saúde, a história da parceria com os governos do estado e da cidade de São Paulo remonta a 1998, pela instalaçáo de uma unidade em Itaim Paulista, distritos dos mais precários a leste do território paulistano. Além dos 260 leitos hospitalares, pronto-socorro, ambulatório de especialidades e outros serviços, conta com uma biblioteca e uma unidade de apoio ao Projeto Jovem Cidadão em parceria com a Secretaria de Justiça e o Ministério Público, por onde passaram 289 jovens, entre os quais aqueles que foram destinados a serviços comunitários como cumprimento de pena por "infraçôes leves”.

Em outro município contíguo à cidade de São Paulo, também a leste, encontrase outro Hospital STX - OSS Itaquaquecetuba, em funcionamento desde 2000, em parceria com o Governo Estadual. A unidade conta com 249 leitos e atende 11 municípios da regiáo. Entre seus projetos, encontram-se: coleta seletiva de resíduos, tratamento de efluentes, Programa de Educaçáo Ambiental (Comunidade e Escola, em parceria com fundação vinculada a uma indústria química); o Projeto Alegrendo junto às crianças internadas; o projeto de prevenção do câncer de mama.

Ainda são responsáveis por uma AMA - Assistência Médica Ambulatorial - a partir de uma parceria entre o Hospital STX e a Prefeitura de São Paulo - que oferece atendimento primário e secundário em saúde, buscando amenizar o fluxo de pacientes destinados ao complexo hospitalar de Cidade Tiradentes e de Itaquera. Tendo como origem a unidade AMA, os pacientes são encaminhados às Unidades Básicas de Saúde ou hospitais responsáveis pela continuidade do acompanhamento clínico; uma AME - Ambulatório Médico de Especialidades Médicas da Zona Leste (departamento da Casa de Saúde STX) -, cuja finalidade é a gestáo e execução de consultas, cirurgias ambulatoriais e exames.

Além desses equipamentos, alguns bastante entrelaçados com outros programas de assistência social, a Organização de Saúde STX se encarrega da implementação e gestão dos NASF (Núcleos de Apoio à Saúde da Família), que

[...] têm a proposta de apoiar as equipes de saúde da família na busca de resoluçôes mais efetivas à complexidade dos problemas de saúde encontrados no território. Suas açóes estão pautadas pelo acolhimento ao usuário e ao trabalho de humanização da atenção, para o desenvolvimento coletivo de açóes que integrem políticas sociais, educaçáo, esporte, cultura, trabalho e lazer. Trata-se de mais um espaço destinado à prevenção de doenças e promoção da saúde $[\ldots]^{16}$

A OS aponta que sua ação tem por base a Portaria no 154 de 24 de janeiro de 2008, que institui as açôes de saúde destinadas a garantir às pessoas e à coletividade condiçôes de bem-estar físico, mental e social. Enuncia como grande objetivo "instituir a plena integralidade do cuidado físico e mental aos usuários do SUS por intermédio da qualificação e complementaridade do trabalho das Equipes de Saúde da Família”. 
Em seu sítio sáo mencionados os seguintes núcleos: Equipes Itaim Paulista: NASF Silva Teles (Jaraguá); NASF D. João Nery (Jardim Campos); NASF Sana Rita (Jardim Robru); NASF Nova Curuçá (Curuçá Velha); NASF Indaiá (KEmel, Atualpa). Equipes Cidade Tiradentes-Guaianases: NASF Barro Branco (Jardim Vitória, Dom Angélico); NASF Carlos Gentile (Inácio Monteiro); NASF Profeta (Ferroviários, Gráficos); NASF Cosmopolita (Jardim Soares); NASF Primeiro de Outubro (Bandeirantes, Fanganielo); NASF Celso Daniel (Santa Luzia). Equipes São Miguel: NASF Santa Inês (União Vila Nova, Adão Manoel); NASF Nitro Operária (Jardim Maia, Nova São Miguel); NASF Tersio Ventura (Pedro José Nunes). Equipes Itaquera: NASF Santo Estevão (Vila Santana, Vila Ramos, Jardim Copa); NASF Santa Terezinha (Gleba do Pêssego, Jardim Helian, Nossa Senhora do Carmo, Santa Maria).

Esses núcleos implementam programas que fazem parte da Estratégia Saúde da Família - que a OS de Saúde STX define como "Estratégia que cria vínculo". ${ }^{17} \mathrm{O}$ programa está implantado

em quase todos os Municípios, com atuaçáo de mais de 28 mil equipes, 16 mil equipes de Saúde Bucal e 218 mil Agentes Comunitários no Brasil. Só na cidade de São Paulo são mais de 1.200 equipes distribuídas em 31 Subprefeituras pertencentes a cinco regionais. Apesar do significativo número, a cobertura na cidade ainda permanece baixa, cerca de 30\% para 783 mil habitantes cadastrados. Sob a orientação da OS de Saúde STX estáo 255 equipes de Estratégia Saúde da Família, sendo elas distribuídas pela Zona Leste: Aricanduva - 03, Cidade Tiradentes - 32, Ermelino Matarazzo - 20, Guaianases - 33, Itaim Paulista - 56, Itaquera - 32, Penha - 7, São Mateus - 33 e São Miguel Paulista - 39. ${ }^{18}$

Nota-se uma ação que pode ser reconhecida como um planejamento minucioso das atividades e açôes sociais e de saúde em âmbito local e territorial. Trata-se do que se poderia denominar Planejamento Social Privado, ${ }^{19}$ constituindo agentes e territorialidades de ação ora mais circunscritas à zona leste - como no caso das ações, práticas e equipamentos de saúde -, ora utilizando outros expedientes de inserção territorial muito mais ampla como as ações vinculadas ao Projeto Guri ou os grandes eventos culturais da cidade.

Em seu discurso a OS de Saúde STX reafirma os ganhos de agilidade e melhoria na prestação de serviços públicos de saúde, bem como sua observância aos princípios que norteiam o Sistema Único de Saúde no Brasil. ${ }^{20}$ Também é preciso notar que em 2001, a Casa de Saúde STX participou da implantação das organizaçôes sociais, o que aconteceu, inicialmente, na zona leste de Sáo Paulo e ao longo das regiôes norte e sul. Assim, há um caráter de pioneirismo nessa participação e na reorganização da Atenção Básica ao se tornar parceira da Secretaria Municipal de Saúde para as subprefeituras de Cidade Tiradentes, Ermelino Matarazzo, Guaianases, Itaquera, Itaim Paulista, São Miguel e São Matheus. ${ }^{21}$ Com a parceria, coube à OS de Saúde STX a contratação, realocação, administração e capacitação de trabalhadores, denominados "colaboradores", para atuar nas respectivas subprefeituras. O contrato ainda contemplava o repasse dos recursos e bens necessários a fim de garantir a execução das atividades, seguindo uma lógica de "autonomia, flexibilidade e agilidade". Em seu discurso, a Organização de Saúde STX afirma:
17 O Programa Saúde da Família foi implantado na zona leste de São Paulo em 1996, por meio de parceria com a Secretaria Estadual de Saúde e, posteriormente, em 2001 com a Secretaria Municipal de Saúde. Passados 13 anos desde a criação, o Programa Saúde da Família evoluiu e atualmente se denomina Estratégia Saúde da Família (ESF), em função de uma nova proposta de reorganização e reestruturação do sistema.

$18 \mathrm{~A}$ OS afirma ainda que nas regiões onde o trabalho da ESF é efetivo os resultados podem ser mensuráveis, pois há uma melhor cobertura de casos prioritários, como: gestantes, diabéticos, hipertensos, crianças menores de dois anos, idosos, pacientes com tuberculose e hanseníase. 0 impacto maior teria sido na diminuição da mortalidade infantil - a cada $10 \%$ de cobertura da ESF a mortalidade infantil diminui em 4\%. Do período de implantação até os dias de hoje a ESF teve importantes conquistas, como a inclusão dos Agentes Comunitários, além da renovação do papel do enfermeiro por meio da ampliação do atendimento clínico, valorização do trabalho multidisciplinar e de equipe, integralidade dos cuidados com profissionais qualificados e ênfase na promoção e prevenção intersetorial.

19 Ver a esse respeito Pantoja (2012). A dissertação define como planejamento social privado a ação extensa e bastante significativa da Vale do Rio Doce no interior do Estado do Maranhão.

20 Tornou-se portanto uma "organização social de acordo com a Lei no 14.132 - Decreto no 47.012. Os princípios do SUS são legalidade, impessoalidade, moralidade e economicidade. Cabe notar que a menção à legalidade é fundamental porque responde a um conjunto de críticas que afirmam que a terceirização das atividades fim nos serviços de saúde é inconstitucional."

21 Note-se que são bairros localizados na chamada zona leste da cidade de São Paulo, que poderiam ser pensados 
em um gradiente de consolidação. Entre eles, Cidade Tiradentes, Guaianases e São Mateus podem ser mencionados como distritos mais pobres classificados como regiões de fronteira e pouco consolidadas da cidade.
22 Ver Pantoja, I. - op. cit.
[...] a parceria de sucesso da instituição com a Secretaria rendeu resultados positivos nos principais indicadores de saúde, o que contribuiu para a conquista do contrato de 'Gestão de Organização Social de Saúde’ para Microrregião de Cidade Tiradentes e Guaianases, região que conta com população estimada em 493.816 mil habitantes. O processo deu-se por meio de licitaçáo e o acordo com o poder público foi firmado em 15/02/2008. Na fase inicial do contrato, a Instituição assumiu a gestão integral de 15 Unidades Básicas de Saúde (UBS) que também contam com o 'Programa Saúde da Família', ao longo do processo, novas unidades foram incorporadas e, em setembro de 2008, foi concluída uma nova etapa com a inclusão da Microrregião de Itaim Paulista.

[...] Entre as responsabilidades contratuais estão: gestão de Unidades pela Organização Social; Apoio à integração territorial com o objetivo de explorar e orientar o trabalho entre as equipes e população atendida (o que é) importante facilitador para identificar os problemas de saúde da comunidade; sistema de pagamento com acompanhamento e controle dos recursos aplicados; novas açóes e Termo de permissão de uso, baseado em metas com reunião de avaliação trimestral, onde serão avaliados os indicadores do Serviço de Atendimento ao Usuário (SAU), educação permanente, comissão de prontuários, cadastro de profissionais, apoio à integração, cobertura PSF e vacinal, qualidade PSF e demanda Assistência Médica Ambulatorial (AMA).

\section{ALGUNS APONTAMENTOS FINAIS}

A primeira observaçáo resultante desses dados, aparentemente desconexos, é exatamente sua articulação. Considerados separadamente, a gestão privada de programas de cultura, de ensino musical a espetáculos e a gestão de equipamentos de saúde em todos os âmbitos (de grandes hospitais terceirizados até a gestão de programas de saúde da família) já apontam para sua extensão, principalmente no escopo da cidade de São Paulo. Quando articulados, a questão se complexifica: tanto porque apontam para um planejamento de captaçáo e investimentos bastante intrincado quanto porque induzem a pensar planejamento local e territorial privado assim como planejamento de um fluxo de captaçôes e investimentos que potencializam a açáo cultural e de saúde. Essas instâncias ainda ganham novas dimensóes quando a elas se somam as práticas de acompanhamento e gestão das famílias, jovens e crianças, tanto do ponto de vista da saúde da família quanto do ponto de vista da "inclusão sociocultural" de crianças e jovens. Uma gestão da vida se esboça em meio a essas articulaçôes entre o trabalho social/cultural e de inclusão, o trabalho em saúde e o acompanhamento de crianças e jovens. Essa dimensão é tão mais instigante e problemática quanto mais se enuncia como uma gestão privada da vida das populaçóes em situaçáo de precariedade, que se estende pelos territórios onde as OS Saúde e Cultura se fazem presentes. Um planejamento social privado ${ }^{22}$ de "inclusão" das famílias, que as toma unidades, se desenha por seu intermédio. É importante destacar esse acoplamento entre práticas educacionais/culturais e de saúde e um trabalho social de acompanhamento, quer pela Estratégia Saúde Família, quer pelo Projeto Guri. Também fica claro que um importante processo de captação tem lugar pelas parcerias com os institutos culturais de grandes empresas, ou diretamente com outras grandes empresas, entre as quais bancos, distribuidoras de energia, grandes construtoras. Essa captação é direta e se 
soma ao repasse de verbas públicas pelos processos de gestáo tanto dos programas de saúde quanto de grandes equipamentos como hospitais, grandes eventos e programas socioculturais como o Projeto Guri.

Outra observação importante diz respeito a um processo de distribuição do trabalho da OS de Saúde STX pelo território da cidade, bem como distribuição territorial de outras práticas da OS de Cultura STX. Se o trabalho social vinculado ao Projeto Guri e ao ensino de música e inclusão social se espraia pelos territórios da cidade de São Paulo, o trabalho de parceria em saúde se concentra na zona leste da cidade e adjacências, estendendo-se para outros municípios também a leste da regiáo metropolitana. Essas formas de territorialização são um resultado: das políticas de terceirização e de instituição de parcerias público-privadas nas áreas de saúde, loteadas entre diferentes entidades, obedecendo critérios vinculados aos bairros e aos interesses e conveniências de cada parceiro; e de uma política de financiamento da cultura e de atividades culturais, que se distribuem de outro modo pelo território e pelas populações mais ou menos "vulneráveis", mais ou menos empobrecidas da cidade. Também é importante notar que as OSs - e a OS STX em particular captam recursos provenientes de imposto devido (além das parcerias com grandes empresas e com o Estado) de modo a "potencializar" sua ação - tanto no caso da saúde como no caso das atividades e práticas culturais, inclusive a Escola de Música Tom Jobim, no centro da cidade de Sáo Paulo ${ }^{23}$ - sempre vinculada a um trabalho social "muito significativo".

Ainda da perspectiva de uma discussão das novas formas e dos novos conteúdos e agentes das políticas sociais e das políticas de combate à pobreza no Brasil - e Sáo Paulo parece ser um caso exemplar desse ponto de vista -, cabe lembrar, como apontam analistas e algumas entidades, bem como as entidades de representaçáo dos médicos (sindicato e conselhos), que a propalada economia de recursos do Estado pode no mínimo ser discutida e questionada, ${ }^{24}$ especialmente quando se tem em vista a captação de recursos públicos por meio de leis de incentivo à cultura que permitem o investimento de fundos públicos na forma de imposto devido, permanentemente sujeitos a uma arbitragem privada da perspectiva de como e onde são investidos. Cabe ainda mencionar a magnitude desses recursos - suficientes para a abertura recente pelas OS STX, de uma unidade universitária privada na zona leste da cidade de São Paulo, que abarca cursos de graduação e de pós-graduação voltados para a saúde, inclusive um curso de Medicina. Observe-se a diversificação de algumas especialidades e formas de atendimento do Hospital de Itaquera, que conta com um serviço de oncologia infantil de ponta, financiado parcialmente por recursos captados por meio das parcerias e gestão privada de grandes equipamentos públicos e com a arrecadação proveniente dos espetáculos e concertos musicais, dos fundos arrecadados via Ministério da Cultura, por meio das leis de incentivo. Quem arbitra sobre seus investimentos? O que restou do caráter público das dimensóes da saúde e da cultura, especialmente aqueles voltados para as populaçóes mais pobres, exatamente aquelas que supostamente são os alvos das propostas e dos mecanismos de inclusão?

Finalmente, é preciso recuperar as consideraçóes de Amélia Cohn sobre a questão das políticas de combate à pobreza no Brasil, seus emaranhados e labirintos. Cohn aponta que a política de saúde e demais políticas sociais brasileiras estariam no fio da navalha. Buscando pensar os liames entre condicionalidades, agentes e programas, e afirma que
23 A Universidade Livre de Música (ULM),com sede no Bom Retiro, foi transferida em 2001 para o prédio localizado no Largo Genera Osório, na Luz, passando a se chamar Centro de Estudos Musicais Tom Jobim e, posteriormente, Escola de Música do Estado de São Paulo - Tom Jobim (EMESP Tom Jobim). Em 2009, a organização social STX passou a administrá-la.

240 Blog FAX Sindical aponta os dados abaixo, no mínimo, reveladores de um descompasso entre o discurso da economia e eficiência e os resultados dos processos de terceirização e parcerias: "A terceirização dos serviços de saúde no estado de São Paulo provocou um rombo de aproximadamente $\mathrm{R} \$ 147$ milhões. Esse valor equivale ao somatório do déficit de 18 hospitais que são administrados por Organizações Sociais de Saúde (OSS) - em que se transfere para instituições filantrópicas o gerenciamento de hospitais públicos. Neste modelo, o poder público continua a arcar todos os gastos de funcionamento e paga mais uma taxa de administração. 0 governo estadual justifica a implementação deste modelo por ser 'exemplo de economia e eficiên- 
cia'. Porém, dos 34 hospitais públicos geridos por OSS, apenas quatro possuem balanço financeiro positivo. 18 hospitais possuem patrimônio negativo e os outros doze não apresentaram balanço referente a 2010. Em 2008 e 2009, o custo total com os hospitais terceirizados foi em média $50 \%$ mais caro do que os hospitais administrados diretamente pelo governo. Os gastos públicos correspondentes aos anos de 2006 a 2009 com as OSS aumentaram $114 \%$ - foram de $R \$ 190$ milhões para R\$ 1,96 bilhão. Um dos hospitais que apresenta déficit - no valor de $\mathrm{R} \$ 4,2$ milhões - é o Hospital Mário Covas [...], gerenciado pela OSS Fundação ABC. 0 seu chefe de neurocirurgia é o médico e ex-secretário de Esporte, Jorge Pagura, acusado de ter ligação com o esquema de fraudes em licitações e pontos de plantões médicos no Sistema Público de Saúde de São Paulo." (Blog "Vi o Mundo", Vivian Fernandes. Blog Fax Sindical, consultado em 15 de agosto de 2012).

$25 \mathrm{COHN}, \mathrm{A}$. Saúde e desenvolvimento social. Saúde e Sociedade, São Paulo, v. 18 , abr./jun. 2009.

Cibele Saliba Rizek é professora associada do Instituto de Arquitetura e Urbanismo da USP (São Carlos). Pesquisadora do CENEDIC - Centro de Estudos dos Direitos da Cidadania da USP. Doutora em Sociologia pela USP. E-mail: cibelesr@uol.com.br
[...] um tema muito pouco desenvolvido [...] é como fica essa questão do Estado produtor, do Estado provedor e do Estado regulador na área da saúde. [...] Como é que nós vamos apostar [...] no caso das OSCIP, na capacidade de regulaçáo do Estado? Todas as análises de regulação [...] vêm mostrando a capacidade que o mercado tem [...] de capturar as agências de regulação com seus interesses, aí sim, privados. [...] Como é que vamos resgatar essa capacidade de regulação do Estado se ela demanda o fortalecimento da dimensão política e o fortalecimento da esfera pública? E isso numa conjuntura em que as restriçóes fiscais [e] os contingenciamentos existem, em que o nosso sistema de proteçáo social está indo para uma linha [de cobertura] da população, que está aumentando os gastos na área social - [...] segundo os últimos dados do Instituto de Pesquisa Econômica Aplicada (IPEA) -, mas que está, ao mesmo tempo, criando um sistema híbrido de proteção social, assumindo, de um lado, políticas que correspondem a direitos e, de outro, programas que correspondem a semidireitos ou quase direitos. O Programa Bolsa Família não é um direito [...] mas é um programa de transferência condicional de renda. Qual é uma das suas condicionalidades? Açôes na área da saúde para gestantes e crianças. Assim, a saúde, que é um direito, para outro programa torna-se uma obrigação, transformando-se num fator restritivo para a população ter acesso ao benefício. No entanto, não resta dúvida de que a condicionalidade da saúde imprime maior eficácia ao setor propriamente dito. Como [...] enfrento essa dubiedade? Percebem como se está caminhando no fio da navalha? A dubiedade é resolvida da seguinte forma: o não cumprimento da condicionalidade significa [...] um questionamento e uma demanda para os governos locais irem atrás da criança que não está vacinada, que não está na escola etc. É muito mais um questionamento para a administração pública do que para a família. Só que isso vem representando o aumento da demanda por serviços, sobretudo nas áreas mais pobres, nos municípios mais pobres. E com isso começa o exercício da bola de neve. Em síntese, creio que o desafio que se apresenta para nós é: [...] qual a relação que se vai estabelecer nesse novo projeto da saúde enquanto questão social, hoje, reatualizada entre as dimensões técnica, política e social das políticas de saúde? [...] Como articular os níveis macro e micro de análise? [...] Tenho me dedicado, nos últimos anos, a discutir as questóes sociais e sempre fiquei intrigada com a questão da porta de saída do Programa Bolsa Família. Isso porque, recentemente, verificam-se muitos avanços em políticas distributivas na área social, mas não em políticas redistributivas, porque políticas redistributivas implicam [...] reformas estruturais na sociedade, investimentos em políticas estruturais. Então [...] as políticas de transferência de renda e políticas de saúde, entre elas, são políticas que funcionam muito para o combate à pobreza; no entanto, a desigualdade está caindo muito pouco em nossa sociedade, porque seu enfrentamento não se dá por meio de políticas distributivas, o combate à desigualdade está nas políticas de caráter estrutural - e acho que é este o novo desafio que a sociedade brasileira tem pela frente..$^{25}$ 


\section{REFERÊNCIAS BIBLIOGRÁFICAS}

BRASIL. Ministério da Cultura. Editais Cultura e Saúde e Rede Saúde e Cultura. http://www. cultura.gov.br. Consultado em 20 de outubro de 2012.

BRASIL. Ministério da Cultura. www.cultura.gov.br/apoioaprojetos. Consultado em 21 de setembro de 2009.

COHN, A. Saúde e Desenvolvimento Social. Saúde e Sociedade, São Paulo, v. 18., abr./jun. 2009.

FERNANDES, V. Vi o Mundo

. In: www.faxsindical.wordpress.com, consultado em 15 de agosto de 2012.

FRENTE NACIONAL CONTRA A PRIVATIZAÇÃO DA SAÚDE. www. frentecontraprivatizacaope.com.br/blog/wp.../DADOS-OSs. 2011. Consultado em maio de 2013.

GEORGES, I., SANTOS, Y. G. A produção da "demanda": viés institucional e implicaçôes políticas da terceirização do trabalho social na periferia de São Paulo. In: CUNHA, N. V., FELTRAN, G. S. Sobre Periferias: Novos conflitos no espaço publico. Rio de Janeiro, Ed. Faperj/Lamparina, 2013.

MAGALHÂES, J. C. As entidades sociais e o surgimento de uma gestão concorrencial do engajamento cívico. In: CABANES, R., GEORGES, I., RIZEK, C., TELLES, V. (orgs.), Saídas de emergência, ganhar/perder a vida em São Paulo. São Paulo, Boitempo, 2011.

MARANHÃO, T. O sentido político das práticas de responsabilidade social empresarial no Brasil. In: CABANES, R., GEORGES, I., RIZEK, C., TELLES, V. (orgs.), Saídas de emergência, ganhar/perder a vida em São Paulo. São Paulo, Boitempo, 2011.

OLIVEIRA, F. e RIZEK, C. A era da indeterminação. São Paulo, Boitempo, 2007.

PANTOJA, I. Planejamento social privado. Rio de Janeiro, IPPUR/UFRJ, 2012. (dissertação de mestrado).

PMSP. LEI MUNICIPAL No 14.132, de 24 de Janeiro de 2006. www.prefeitura.sp.gov.br/ cidade/secretarias/saude/.../index.php?p=6196. Consultado em 15 de agosto de 2012.

PMSP. Prefeitura da Cidade de São Paulo. http://www.prefeitura.sp.gov.br/cidade/secretarias/ upload/saude/arquivos/publicacoes/Boletim_CEInfo_Censo_02.pdf. Consultado em 15 de gosto de 2012

SEGNINI, L. O que permanece quando tudo muda. Cadernos do CRH vol 24, número especial, 2011.

A B S T R A C T This article is based on research that pointed to new ways of raising funds through the promotion of cultural practices that are interconnected to the management of public health services in the Eastern Zone of the City of São Paulo, under the direction of private social organizations. The cross between fundraising, outsourced management of culture and health equipment points to an unprecedented relationship between the sectors of these practices, which sets up what can be identified as a private social planning. This process redrew the margins of the State redefining the relationship between social programs and policies and poor population in the largest Brazilian city. The peripheral neighborhoods of the Eastearn outskirts São Paulo became an experimental field of these practices, more than classical character of precarious forms of life or the place of origin of social movements, demands, subjects, right languages, as they were known specially from the 80 's Brazilian sociological literature.

K E Y W O R D S Social policy; public policies; privatization; urban peripheries 